\title{
Evaluation of a 0 -hour/1-hour algorithm in the diagnosis of myocardial infarction with high-sensitivity cardiac troponin T1
}

\section{Jaspreet Kaur Khaira}

10.1136/ebmed-2017-110830

\section{Correspondence to:}

Dr Jaspreet Kaur Khaira,

Oxford University Hospitals

NHS Foundation Trust,

Oxford OX3 9DU, UK;

jaspreet.khaira@ouh.nhs.uk
Using a highly sensitive assay of serum troponin $\mathrm{T}$ in patients with suspected myocardial infarction might help in early diagnosis, but the method needs thorough clinical assessment before implementation.

\section{Summary of evidence}

The High Sensitivity Cardiac Troponin T Assay for Rapid Rule-out of Acute Myocardial Infarction trial was a prospective, multicentre, diagnostic study done at 12 sites, across three continents to validate the diagnostic accuracy of the troponin T 0-hour/1-hour algorithm for rule-in and rule-out of acute myocardial infarction. ${ }^{1}$

Current troponin assays for the diagnosis of myocardial infarction usually require serial sampling between 8 and 24 hours, depending on the specific assay/local protocols. This time interval contributes to 'rule-in' delays, delaying treatment, and 'rule-out' delays, costing time, money and resources.

Stratifying patients with symptoms suggestive of acute myocardial infarction into three groups, by measuring the concentrations of cardiac troponin $\mathrm{T}$ at the time of presentation and after 1 hour, using a highly sensitive assay, could therefore speed up diagnosis and treatment, rule out disease more efficiently and save costs. The algorithm used was:

- 'rule-in' (0 hour $\geq 52 \mathrm{ng} / \mathrm{L}$ or $\Delta 1 \mathrm{~h} \geq 5 \mathrm{ng} / \mathrm{L}$ ).

- 'rule out' ( 0 hour $<12 \mathrm{ng} / \mathrm{L}$ and $\Delta 1 \mathrm{~h}<3 \mathrm{ng} / \mathrm{L})$.

- 'observational zone' (0hour $12-52 \mathrm{ng} / \mathrm{L}$ and $\Delta 1 \mathrm{~h}$ 3-5 ng/L).

The authors recruited patients presenting to the emergency department with symptoms suggestive of myocardial infarction (chest pain/angina), with onset of pain or maximum discomfort of pain within the previous 6 hours. Written informed consent was obtained and blood samples taken at 0 hour, 1 hour, 2 hours and 4 to 14 hours. Patients underwent standard clinical assessment and treatment (table 1).

\section{Summary box}

A highly sensitive serum troponin T assay has been claimed to be useful in ruling a myocardial infarction in or out soon after presentation.

- However, performance measures for diagnostic tests should be thought of in terms of real patients, and not taken at face value.

- Changes in biomarker concentrations over time may be superior to single cut-off values.

\begin{tabular}{|c|c|c|c|}
\hline $\begin{array}{l}\text { Algorithm } \\
\text { classification }\end{array}$ & $\begin{array}{l}\text { Acute } \\
\text { myocardial } \\
\text { infarction }\end{array}$ & $\begin{array}{l}\text { Non-acute } \\
\text { myocardial } \\
\text { infarction }\end{array}$ & Total \\
\hline Rule-out status & 7 & 806 & 813 \\
\hline Observational zone & 64 & 221 & 285 \\
\hline Rule-in status & 142 & 42 & 184 \\
\hline Total & 213 & 1069 & 1282 \\
\hline
\end{tabular}

For the 1282 patients in the analysis, performance measures for the troponin $\mathrm{T}$ assay can be found in table 2.

Two independent cardiologists adjudicated the diagnoses using all the available evidence. They were able to access standard troponin I results, but remained blinded to troponin T concentration. Secondary outcome measures included mortality at 30 days and 1 year.

In the 'observational' group, 22.5\% had acute myocardial infarction. Cumulative 30-day mortality was $0.1 \%, 0.7 \%$ and $2.7 \%$ in patients classified as rule-out, observational zone and rule-in respectively.

\section{Critical analysis}

While this study, at first glance, demonstrated encouraging sensitivity, specificity and NPV for the algorithm, a number of methodological and statistical issues must be considered.

The authors studied a specific patient group, who may not be representative of the population at large: patients were only included if they presented to the emergency department (as opposed to primary care), with chest pain that had started no more than 6 hours earlier, only when study staff were present to obtain consent and not, for example, at night or during weekends. It is therefore difficult to generalise the widespread use of this assay for all chest pain presentations, let alone for other symptoms of myocardial infarction, which the authors neglect to include/mention.

Furthermore, a significant number of patients are excluded (long-term renal replacement therapy, trauma, cardioversion, defibrillation, thrombolytic therapy before inclusion, coronary artery bypass grafting within the last month, admission for myocardial infarction within the past 3 weeks and pregnancy/breastfeeding) further limiting the generalisability of the results. The use of the troponin $\mathrm{T}$ assay in place of existing troponin assays also requires a comparison of the performance measures of existing troponin assays.

'Observational zone' patients form an ambiguous category and are used to inflate performance measures. They are counted as 'true positives' along with the 'rule-in' group for sensitivity calculations and as 'true 


\begin{tabular}{|c|c|c|c|}
\hline \multicolumn{4}{|l|}{ Table 2} \\
\hline Performance measures & $\begin{array}{l}\text { Estimate, } \\
\%\end{array}$ & $95 \% \mathrm{Cl}$ & Counts \\
\hline Sensitivity & 96.71 & $\begin{array}{l}93.35 \text { to } \\
98.67\end{array}$ & $206 / 213$ \\
\hline Specificity & 96.07 & $\begin{array}{l}94.73 \text { to } \\
97.15\end{array}$ & $1027 / 1069$ \\
\hline $\begin{array}{l}\text { Negative predictive } \\
\text { value (NPV) }\end{array}$ & 99.14 & $\begin{array}{l}98.23 \text { to } \\
99.65\end{array}$ & $806 / 813$ \\
\hline $\begin{array}{l}\text { Positive predictive } \\
\text { value (PPV) }\end{array}$ & 77.17 & $\begin{array}{l}70.42 \text { to } \\
83.03\end{array}$ & $142 / 184$ \\
\hline
\end{tabular}

negatives' along with the 'rule-out' group for specificity calculations.

Lastly, a point relating to the interpretation of the performance measures of diagnostic tests - it is all too easy to satisfy oneself with high specificities, sensitivities, NPVs and PPVs without thinking about 'real-life' patients. Discussions in our Journal Club highlighted that while a 'rule-out' sensitivity of $96.7 \%$ appeared superficially impressive, this essentially meant that for every 1000 patients with myocardial infarction, 33 would walk away with a falsely negative test result. Similarly, a 'rule-in' specificity of $96.1 \%$, means that for 1000 patients without myocardial infarction, 39 would test positive and undergo unnecessary/potentially harmful intervention. One must also consider that NPV/ PPV depend on disease prevalence within the population and so a PPV of only $77.2 \%$ in this population of emergency department chest pain presentations, where myocardial infarction is more prevalent than, say, in primary care, is perhaps less impressive than at first glance. Thinking about these statistics in terms of actual patients is helpful in realising that such tests should not be thought of as 'diagnostic', but rather aids in decision-making, used in combination with clinical experience and expertise.

Acknowledgements Carl Heneghan, Nuffield Department of Primary Health Care Sciences, Oxford for facilitating discussions at Journal Club and feedback on manuscript. Brian Angus, Nuffield Department of Medicine, OUH for facilitating discussions at Journal Club.

Contributors JKK presented the study at the OUH F1 Journal Club on 7 September 2017 and wrote the manuscript.

Competing interests None declared.

Provenance and peer review Commissioned; internally peer reviewed.

( $)$ Article author(s) (or their employer(s) unless otherwise stated in the text of the article) 2017. All rights reserved. No commercial use is permitted unless otherwise expressly granted.

\section{Reference}

1 Mueller C, Giannitsis E, Christ M, et al. Multicenter evaluation of a 0-hour/1-hour algorithm in the diagnosis of myocardial infarction with high-sensitivity cardiac troponin T. Ann Emerg Med 2016;68:76-87. 